\title{
Regulation of the New Coexpressed CD55 (Decay-Accelerating Factor) Receptor on Stomach Carcinoma Cells Involved in Antibody SC-1-Induced Apoptosis
}

\author{
Frank Hensel, Ralph Hermann, Stephanie Brändlein, Veit Krenn, Bernd Schmausser, \\ Steffen Geis, Hans Konrad Müller-Hermelink, and H. Peter Vollmers \\ Institute for Pathology, University of Würzburg, Würzburg, Germany
}

\begin{abstract}
SUMMARY: The human monoclonal antibody SC-1 was isolated from a patient with a diffuse-type adenocarcinoma of the stomach using somatic cell hybridization. The immunoglobulin (Ig)M antibody reacts specifically with diffuse- (70\%) and intestinal-type (25\%) gastric adenocarcinoma and induces apoptosis in vitro and in vivo. When used in clinical trials with stomach carcinoma patients, significant apoptotic and regressive effects in primary tumors have been observed with the antibody SC-1. The SC-1 receptor is a new 82 kd membrane-bound isoform of glycosylphosphatidylinositol (GPI)-linked CD55 (decayaccelerating factor, DAF). CD55 is known to protect cells from lysis through autologous complement and is coexpressed with the ubiquitously distributed $70 \mathrm{kd}$ isoform. The SC-1-specific CD55 isoform is up-regulated shortly after antibody binding, followed by an internalization of the antibody/receptor-complex, whereas the membranous expression of wild-type CD55 remains unchanged. The apoptotic process is marked by cleavage of cytokeratin 18, indicating the involvement of caspase- 6 in the apoptotic process. In contrast to other apoptotic pathways, a cleavage of poly(ADP-ribose)polymerase (PARP) is not observed. The expression of the cell-cycle regulator c-myc becomes up-regulated, whereas expression of topoisomerase $I l \alpha$ is down-regulated. Induction of apoptosis leads to an increase in the internal $\mathrm{Ca}^{2+}$ concentration, which is not necessary for the apoptotic process but for the transport of newly synthesized SC-1-specific CD55 isoform to the membrane. (Lab Invest 2001, 81:1553-1563).
\end{abstract}

$M$ alignant cells re-express, mask, or modify surface structures to fulfill requirements for a higher proliferation rate, to escape immune response mechanisms, or just through happenstance. However, in most cases, these "new" structures allow the immune system to recognize, attack, and remove transformed cells at early stages. Manifest tumors are therefore not the result of a missing qualified immune response, but instead a matter of quantity. Cancer patients represent an enormous source of tumorspecific and -reactive reagents, such as cells, factors, and antibodies. Human hybridomatechnology offers an ideal tool for isolating and establishing human tumor-specific antibodies for therapy and diagnosis.

We have recently described the human antibody $\mathrm{SC}-1$, isolated from a patient with a signet ring cell carcinoma of the stomach (Vollmers et al, 1989). This immunoglobulin (lg)M antibody induces apoptosis of gastric cancer cells in vitro and in vivo and is being used successfully in clinical trials (Vollmers et al, 1998b). The receptor of SC-1 was found to be a

Received August 3, 2001.

This project was partly supported by the Deutsche Krebshilfe e.V.

Address reprint requests to: Prof. Dr. H. Peter Vollmers, Institut für Pathologie, Universität Würzburg, Josef-Schneider-Str. 2, D-97080 Würzburg, Germany.E-mail: path027@mail.uni-wuerzburg.de modified version of CD55 (decay-accelerating factor, DAF). This protein protects host tissues from autologous complement activation and is expressed on all cell types that are likely to have contact with the complement system, ie, epithelial cells (Koretz et al, 1992), lymphocytes, monocytes, platelets (NicholsonWeller et al, 1985), and endothelial cells (Asch et al, 1986). It acts by dissociating the classical and alternative pathway $\mathrm{C} 3$ convertases, and there are various isoforms in existence (Lublin et al, 1986). CD55 is expressed in two different isoforms (DAF-A and DAF-B) generated by differential splicing. Whereas DAF-A is secreted from cells, DAF-B is linked to cells by a glycosylphosphatidylinositol (GPI) anchor (Caras et al, 1987). Both forms are further modified by different glycosylation patterns, resulting in molecular weight sizes from 55 to $100 \mathrm{kd}$ (Hara et al, 1993).

Besides these well-described functions of CD55, it has become more and more obvious that this receptor can also act as a signal-transducing molecule. With monoclonal antibodies directed against CD55, human monocytes can be activated in vitro (Shibuya et al, 1992). These changes in the cell cycle might be transmitted through src-kinases, which are associated with the GPI anchor of CD55 (Parolini et al, 1996; Shenoy-Scaria et al, 1992).

Another aspect of CD55, which makes it interesting as a target for tumor therapy, is the fact that this 
molecule is overexpressed on various tumors. Overexpression has been found in, eg, breast, colon, and stomach carcinoma (Hofman et al, 1994; Koretz et al, 1992; Niehans et al, 1996), and this overexpression makes CD55 a suitable target for cancer vaccines in the treatment of colon carcinoma (Spendlove et al, 1999). Vaccination with a human anti-idiotype antibody that mimics CD55 was used for adjuvant treatment of colon carcinoma and resulted in activation of a cellular anti-tumor response (Durrant et al, 1995, 2000). However, this overexpression of CD55 and other complement-inactivating molecules limits therapeutical approaches that depend on the help of complement, as in antibody-dependent cellular cytotoxicity (ADCC) (Gorter and Meri, 1999). This can be circumvented by the use of bispecific antibodies that bind to CD55 and a tumor-associated molecule, thereby enhancing C3 binding and cell lysis (Blok et al, 1998).

Furthermore, there is some evidence that CD55 and other GPI-linked molecules (CD14, CD24, CD59) might be involved in apoptotic processes (Devitt et al, 1998). A participation of CD55 in apoptosis was observed with regard to human polymorphonuclear leukocytes (PMN), in which a reduced expression of CD55, together with CD59, is closely related to the appearance of apoptotic morphology (Shapiro et al, 1994). In paroxysmal nocturnal hemoglobinuria, a genetically determined hematopoietic stem cell disorder that results in the absence of GPI-linked molecules, including CD55, the cells are also protected from apoptosis when induced by ionized irradiation (Brodsky et al, 1997).
A clear association of CD55 with apoptosis has been shown with the human monoclonal antibody $\mathrm{SC}-1$. This antibody reacts with a carbohydrate residue on a new isoform of GPI-linked CD55 (subsequently named CD55 $5^{\mathrm{SC}-1}$ ), and induces tumor-cellspecific apoptosis in vitro and in vivo. The CD55 $5^{\mathrm{SC}-1}$ isoform is overexpressed on gastric carcinoma cells (Hensel et al, 1999) and has a molecular weight of approximately $82 \mathrm{kd}$.

In this paper, we show that stomach carcinoma cells express two different forms of CD55/DAF on the cell surface: the normal $70 \mathrm{kd}$ isoform that protects against complement, and in addition, the new $\mathrm{CD}_{5} 5^{\mathrm{SC}-1}$ apoptosis receptor. Furthermore, we show new phenomena associated with SC-1-induced apoptosis, focusing on membrane-associated and cytoplasmic events.

\section{Results}

\section{Expression of CD55 $5^{W T}$ and $C D 55^{S C-1}$ on Different Cells}

To investigate the expression of the CD55 isoforms biochemically, membrane extracts from the stomach cancer cell line 23132 were blotted with a commercial anti-CD55 antibody and with antibody SC-1. The cervix carcinoma cell line HeLa served as a control for the 70-kd form of CD55. As seen in Figure 1a, two different molecules appear on the stomach cancer cells: a strongly stained $70-\mathrm{kd}$ and a weakly stained 82-kd form. On HeLa cells next to the 70-kd CD55 protein, there is a very strong stained $60-\mathrm{kd}$ band, which seems to be a lower weight isoform of CD55 ${ }^{\mathrm{WT}}$. With antibody SC-1, only the 82-kd band identified as

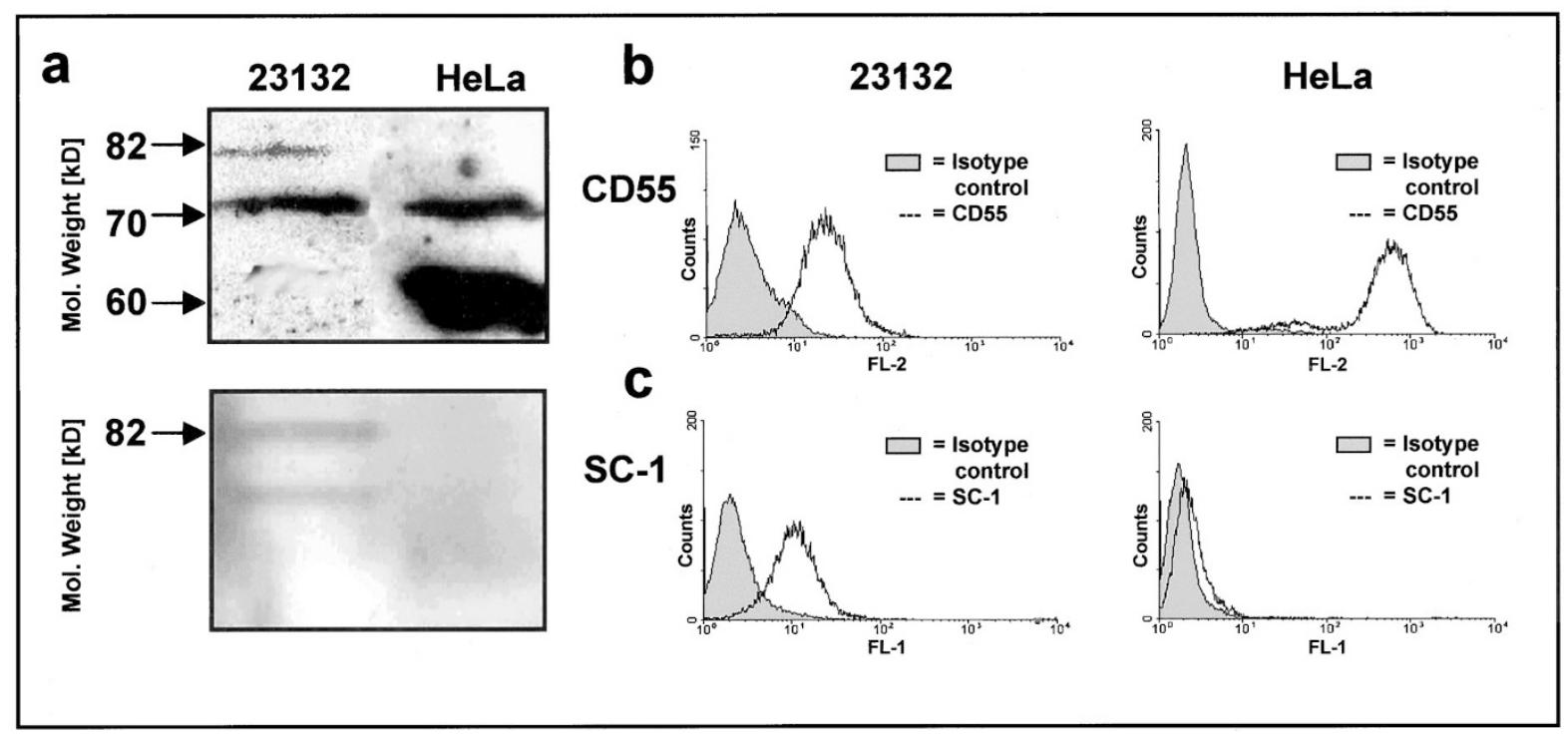

Figure 1.

Expression of CD55 wild-type (CD55 ${ }^{\mathrm{WT}}$ ) and SC-1-specific CD55 isoform (CD55 ${ }^{\mathrm{SC}-1}$ ) on different cells. The expression of both CD55 isotypes were tested by Western blot and FACS analysis. For Western blot analysis, membrane extracts from 23132 and cervix carcinoma cell line (HeLa) tumor cells were run on SDS gels and blotted on nitrocellulose filters and either stained with anti-CD55 antibody or with SC-1. For FACS analysis, cells were additionally stained with mouse or human isotype-matched control antibodies. a. HeLa cells express two isoforms of CD55 of approximately 60 and $70 \mathrm{kd}$, whereas in 23132 cells the $70-\mathrm{kd}$ and the SC-1-specific 82-kd form were detectable. SC-1 staining was not observable in HeLa cells, whereas staining of the 82-kd CD55 ${ }^{\text {SC-1 }}$ proteins was visible in the cell line 23132. Staining of additional protein is due to unspecific cross-reaction as described earlier. b, FACS analysis with anti-CD55 shows binding to cell lines 23132 and HeLa compared with the isotype-matched control. c, On cell line 23132, SC-1 shows binding compared with the isotype-matched control, whereas there is no binding found on HeLa cells. 
CD55 ${ }^{\mathrm{SC}-1}$ is stained on stomach cancer cells, whereas there is no reaction on HeLa cells. The second stained band is due to cross-reaction with cytoplasmic Lupus $\mathrm{Ku}$ autoantigen described previously (Hensel et al, 1999).

To confirm the Western blot analysis, we performed flow cytometry by staining both cell lines with SC-1 or anti-CD55 antibody. The flow cytometry clearly shows that the anti-CD55 antibody binds to the 23132 and HeLa cells (Fig. 1b), whereas antibody SC-1 clearly binds to 23132 cells, but not to HeLa cells (Fig. 1c).

\section{Internalization of $\mathrm{CD}^{5 \mathrm{SC}-1}$ on Cell Line 23132 after Induction of Apoptosis}

We further examined the membranous expression of $\mathrm{CD}_{5} 5^{\mathrm{WT}}$ and $\mathrm{CD} 55^{\mathrm{SC}-1}$ in cell line 23132 after the induction of apoptosis with $40 \mu \mathrm{g} / \mathrm{ml}$ of SC-1 by flow cytometry with anti-CD55 and SC-1 antibodies. Flow cytometry shows that $\mathrm{CD} 55^{\mathrm{SC}-1}$ expression remains unchanged for 24 hours, whereas there is a clear decrease in staining with antibody SC-1 after 48 hours. After 72 hours, SC-1 staining is restored (Fig. 2, a to d). In contrast, expression of CD55 ${ }^{\mathrm{WT}}$ remains stable for the measured period (Fig. 2, e to h). Because both CD55 isoforms arise by posttranslational modification and are not different gene products, these differences must occur as a result of the internalization of $\mathrm{CD} 55^{\mathrm{SC}-1}$ after the binding of SC-1. These data were confirmed by cytospin preparations (data not shown). Controls were performed by staining cells with $40 \mu \mathrm{g} / \mathrm{ml}$ of chrompure human IgM for the indicated times.

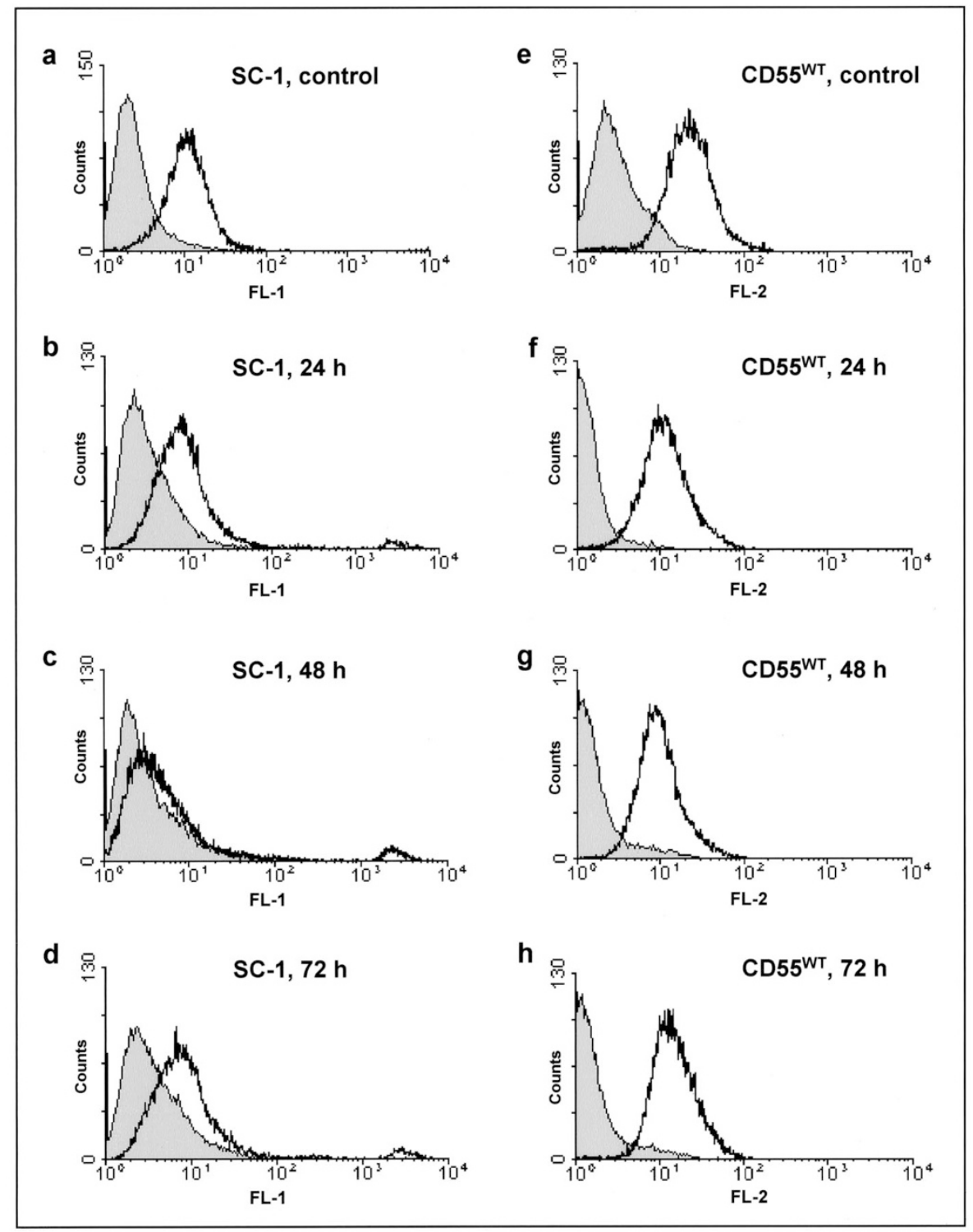

Figure 2.

Expression of $\mathrm{CD} 55^{\mathrm{SC}-1}$ and $\mathrm{CD} 55^{\mathrm{WT}}$ after induction of apoptosis by SC-1. Cells were incubated for the indicated times with $40 \mu \mathrm{g} / \mathrm{ml}$ of $\mathrm{SC}-1$, and after trypsinization, cells were analyzed for expression of $\mathrm{CD}_{5} 5^{\mathrm{SC}-1}(\mathrm{a}-\mathrm{d})$ and $\mathrm{CD}_{5} 5^{\mathrm{WT}}(\mathrm{e}-\mathrm{h})$ by flow cytometry. Additionally, cells were stained with mouse or human isotype-matched control antibodies. Gray area indicates isotype-matched controls; black line indicates cells stained by SC-1 and CD55 


\section{Cleavage of Cytokeratin 18}

The degradation of apoptotic epithelial cells is accompanied by the proteolytic cleavage of cytokeratin 18 (Caulin et al, 1997). We investigated the cleavage of cytokeratin 18 in cell line 23132 after SC-1-induced apoptosis using the M30 CytoDeath kit. Cytokeratin 18 cleavage starts after 24 hours, as determined by immunohistochemical staining (Fig. 3b). After 48 hours, cleavage is completed, and apoptotic bodies are released from the cells (Fig. 3c). Figure 3, $d$ to $f$, shows that approximately $30 \%$ of the cells are undergoing apoptosis. Controls were performed by treating cells for equal periods with $40 \mu \mathrm{g} / \mathrm{ml}$ of chrompure human IgM antibody without inducing cytokeratin 18 cleavage (data not shown).

\section{Effect of Inhibition of Caspase-6 and Caspase-3}

The cleavage of cytokeratin 18 indicates the involvement of caspase- 6 in the apoptotic process induced by SC-1. To confirm the participation of caspase- 6 in the degradation process, the effect of caspase- 6 inhibitor Val-Glu-Iso-Asp-aldehyde (VEID-CHO) on apoptosis was investigated. Cells were incubated overnight with increasing concentrations of the inhibitor VEID-CHO, followed by incubation with $40 \mu \mathrm{g} / \mathrm{ml}$ of SC-1 for 24 hours. The effect of inhibition of caspase- 6 was measured using CellDeath ELISA. Surprisingly, low amounts of inhibitor increased apoptotic cell death, whereas high concentrations clearly inhibited apoptosis (Fig. 4a), indicating that recruitment of caspase-6 is necessary for SC-1-induced apoptosis.

In a recent publication (Hensel et al, 1999), we showed that caspase-3 is activated in SC-1-induced apoptosis. Because of the surprising results obtained from the inhibition of caspase-6, we investigated whether the inhibition of caspase-3 by Asp-Glu-ValAsp-aldehyde (DEVD-CHO) has a comparable effect on SC-1-induced apoptosis. Here, we also found an increase in apoptotic cell death with increasing concentrations of inhibitor. Cells incubated with $500 \mathrm{~nm}$ of DEVD-CHO showed an absorption approximately three times higher, whereas incubation with inhibitor without SC-1 did not have any effect on spontaneous apoptosis (Fig. 4b).

\section{Molecular Analysis of SC-1-Induced Apoptosis}

The occurrence of poly(ADP-ribose)polymerase (PARP) cleavage was investigated by Western blot analysis, using whole cell extracts from SC-1-induced cells and murine anti-PARP antibody. In five indepen-

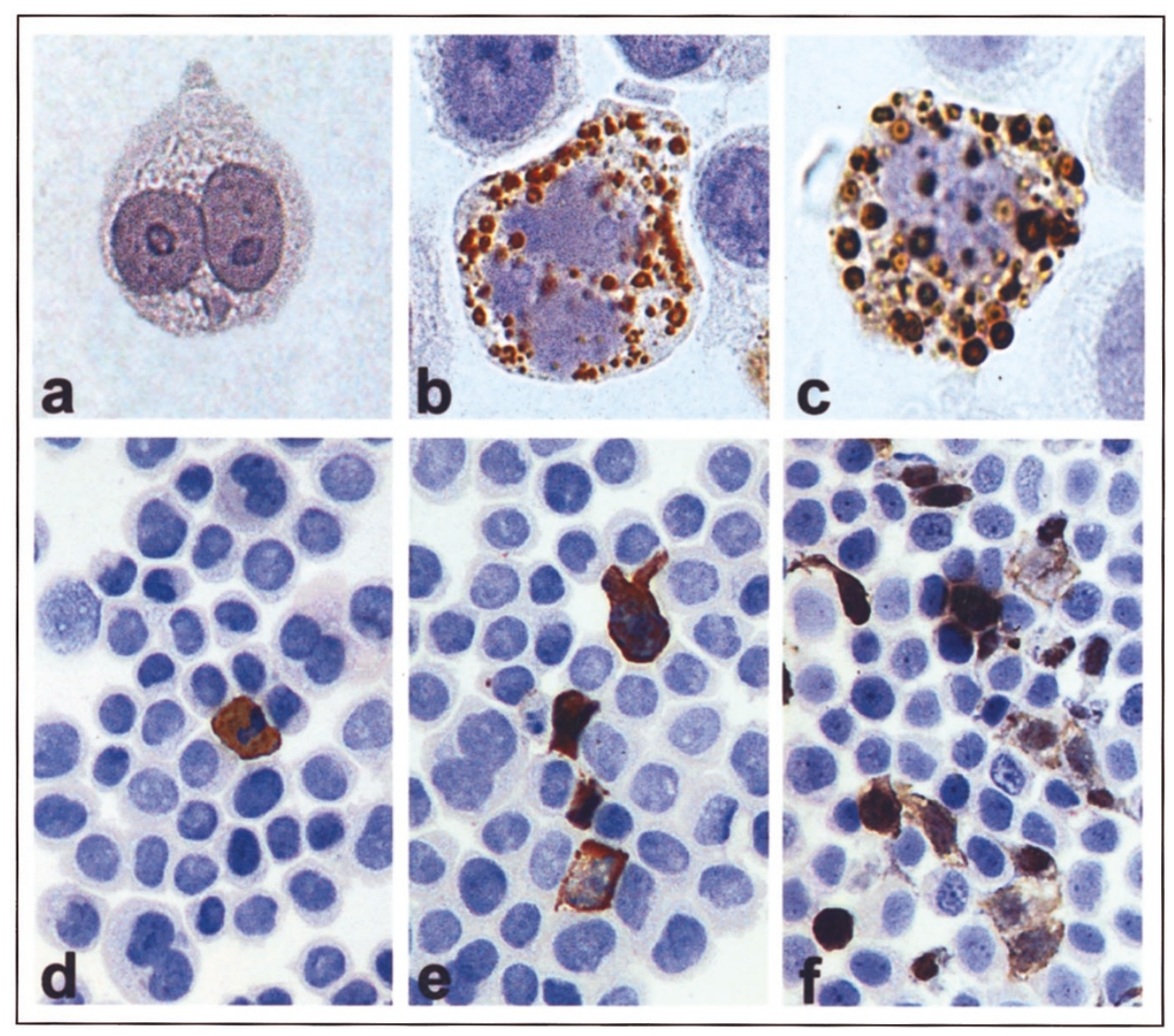

Figure 3.

Cleavage of cytokeratin 18 in SC-1-induced apoptosis. Immunohistochemical staining of cytospins reveals that 24 hours after the induction of apoptosis, cleavage of cytokeratin 18 starts (b), and after 48 hours, apoptotic bodies are released from the cells (c). In Panel a, a nonapoptotic cell is shown (magnification, $\times 400$ ). The overview shows a low amount of apoptosis in uninduced cells (d), whereas SC-1-induced apoptosis begins after 24 hours (e). After 48 hours, approximately $30 \%$ have undergone apoptosis as shown by cytokeratin 18 cleavage $(\mathrm{f})$ (magnification, $\times 400$ ). 


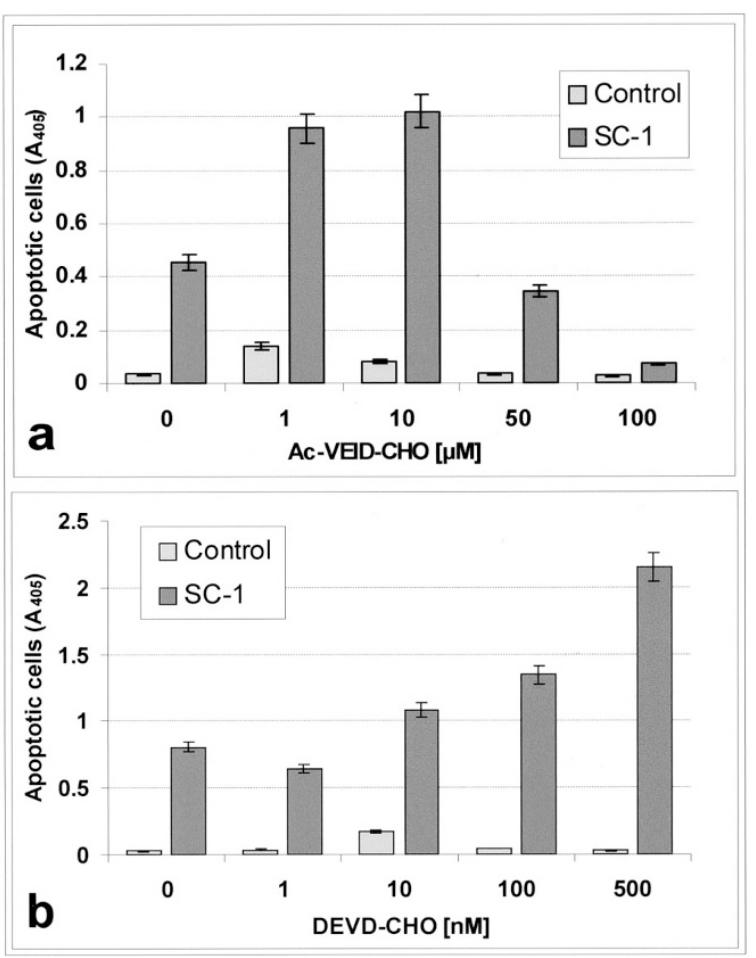

Figure 4.

Inhibition of caspase- 6 and caspase- 3 by specific inhibitors. Cells were incubated overnight with increasing amounts of caspase inhibitor and then for another 24 hours with $40 \mu \mathrm{g} / \mathrm{ml}$ of SC-1. Apoptotic cells were determined by CellDeath ELISA. a, Effect of caspase-6 inhibitor VEID-CHO. Low concentrations of inhibitor increase apoptosis, whereas high concentrations clearly inhibit apoptosis. b, Effect of caspase-3 inhibitor DEVD-CHO. An increase in apoptotic cells with increasing concentrations of inhibitor is observable, whereas incubation with only DEVD-CHO does not show any effect.

dent assays, there was no observable PARP cleavage, which would have been marked by the occurrence of an 85-kd cleavage product (Cosio et al, 1994) (Fig. 5a). The induction of apoptosis was confirmed by measurement of caspase- 3 and caspase- 8 activity as published earlier (Hensel et al, 1999), and the func- tionality of the anti-PARP antibody was confirmed by Western blot analysis with lysates of Fas-induced cells (data not shown).

To investigate the changes in the cell cycle after the induction of apoptosis, the expression of topoisomerase II $\alpha$ was tested by Western blot analysis. Topoisomerase $\| \alpha$ is a key enzyme in the cell cycle by virtue of being involved in DNA replication (Schmitt et al, 1999). Therefore, the reduced expression of topoisomerase II $\alpha$ after SC-1-induced apoptosis indicates cell-cycle arrest for at least a fraction of the cells (Fig. 5b).

The transcription factor c-myc has been shown to be involved in various apoptotic processes or to induce apoptosis by transfection in cells (Berstad and Brandtzaeg, 1998). Because c-myc is not involved in all apoptotic processes, we investigated the expression pattern of c-myc after SC-1-induced apoptosis. A clear increase in c-myc expression was found 5 minutes after induction of apoptosis, followed by a decrease after 1 hour (Fig. 5b). Control for nonspecific effects induced by human IgM was performed by incubating cells with $40 \mu \mathrm{g} / \mathrm{ml}$ of chrompure human IgM antibody without any changes in the expression pattern of any of the proteins described above (data not shown).

\section{Relation between Intracellular $\mathrm{Ca}^{2+}$ Concentration and Apoptosis}

To investigate whether the induction of apoptosis by $\mathrm{SC}-1$ is accompanied by changes of the intracellular calcium concentration $\left[\mathrm{Ca}^{2+}\right]_{i}$, we measured the $\left[\mathrm{Ca}^{2+}\right]_{\mathrm{i}}$ of cell line 23132 after induction with $\mathrm{SC}-1$ and control antibody (chrompure human IgM), using an Axiovert TV microscope. Approximately 1 minute after the addition of SC-1 antibody, a significant increase of $\left[\mathrm{Ca}^{2+}\right]_{\mathrm{i}}$ was observed, whereas the control antibody did not have any effect on $\left[\mathrm{Ca}^{2+}\right]_{i}$ (Fig. 6a).

To investigate the role of $\left[\mathrm{Ca}^{2+}\right]_{i}$ in detail, cells were incubated for 3 hours with increasing amounts of

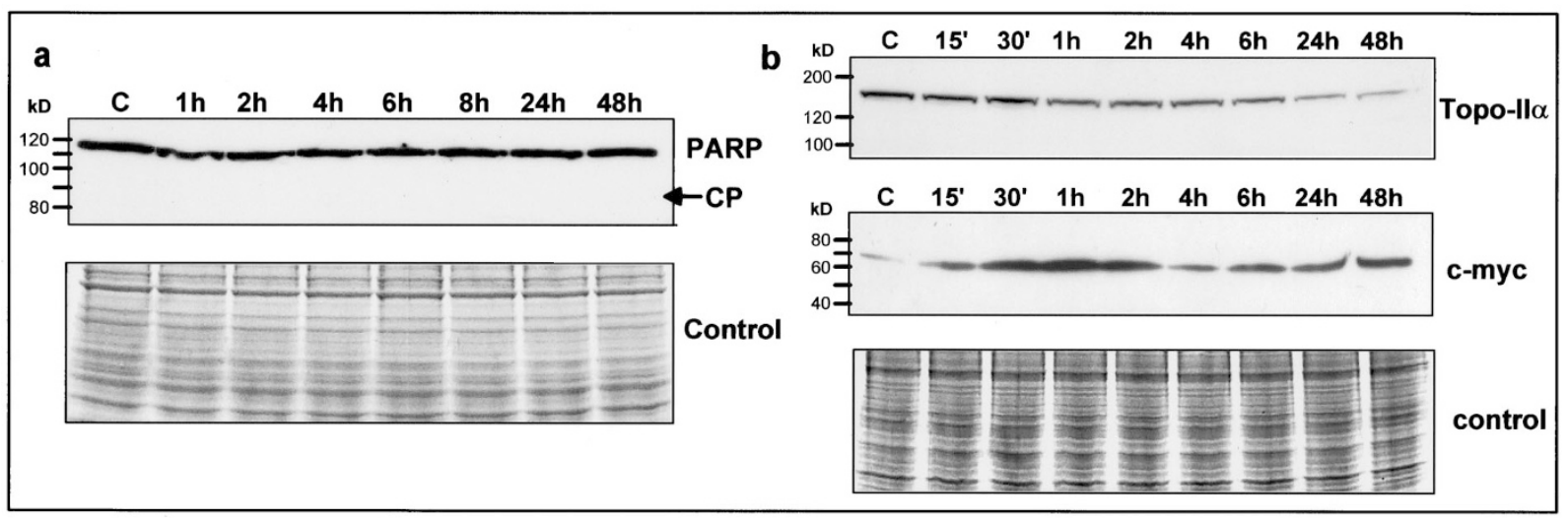

Figure 5.

Western blot analysis of SC-1-induced cells. Cell line 23132 was induced with $40 \mu \mathrm{g} / \mathrm{ml}$ of SC-1 for the periods indicated above, and then whole cell lysates and Western blots were prepared. Coomassie-stained gels shown below the blots were used as controls for equal protein concentrations loaded on lanes. a, Determination of poly(ADP-ribose)polymerase (PARP) cleavage by anti-PARP antibody. CP indicates expected size of PARP cleavage product. Cleavage of PARP was not detectable at all. b. Staining with anti-topoisomerase $\| \alpha$ antibody as marker for cellular proliferation. A reduced expression of topoisomerase $\| \alpha$ could be observed after SC-1-induced apoptosis. Expression of c-myc detected by staining with anti-c-myc antibody. Five minutes after induction of apoptosis, an increased c-myc expression was found, followed by a decrease after 1 hour. 
a

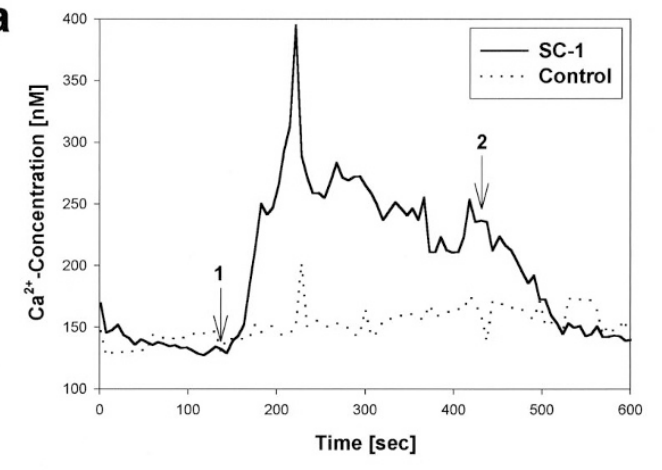

b

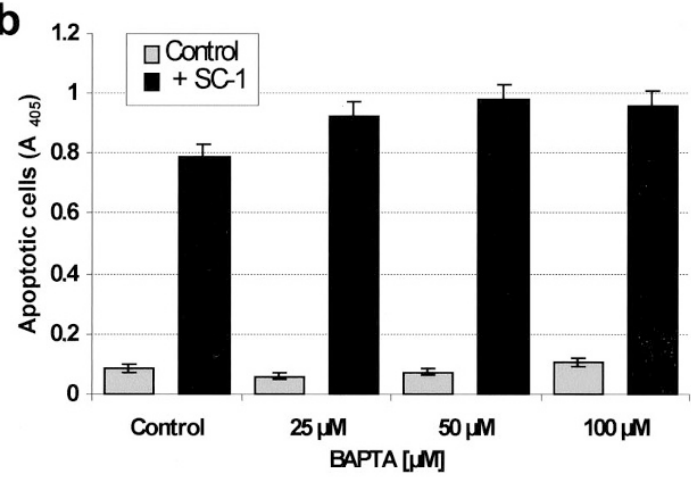

C

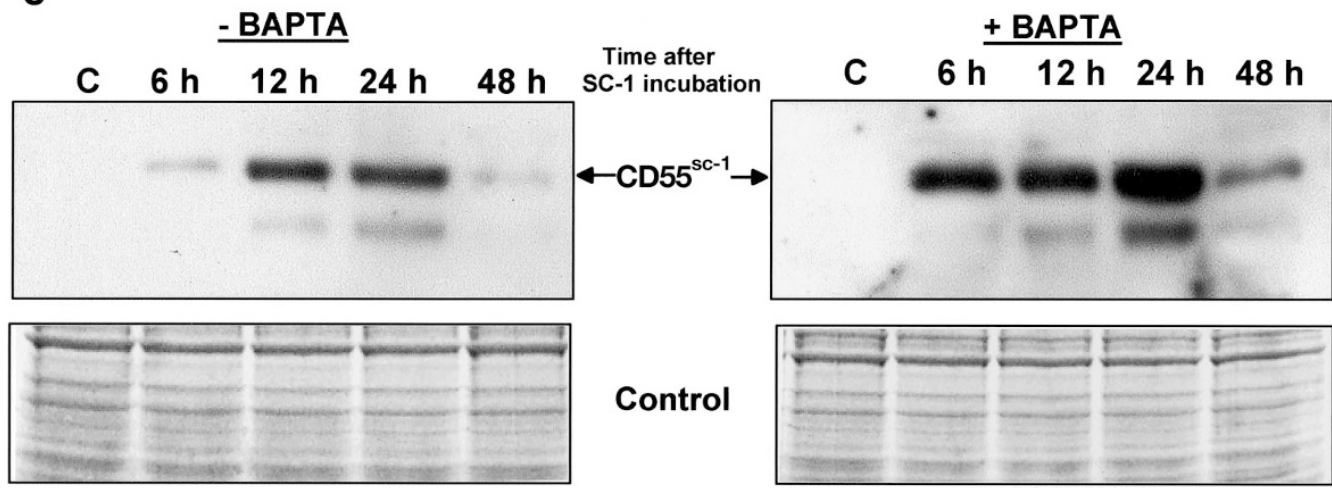

Figure 6.

Participation of $\left[\mathrm{Ca}^{2+}\right]_{i}$ in the apoptotic process. a, Measurement of $\left[\mathrm{Ca}^{2+}\right]_{i}$ after SC-1 induction: Cells were washed with Ringer solution, and, at Point 1 , SC-1 (40 $\mu \mathrm{g} / \mathrm{ml})$ or control antibody chrompure human IgM $(40 \mu \mathrm{g} / \mathrm{ml})$, diluted in Ringer solution, was added. At Point 2, cells were washed with Ringer solution. A 2.7-fold increase in intracellular $\mathrm{Ca}^{2+}$ concentration was observed after approximately 50 seconds of induction with SC-1. b, Effect of $\mathrm{Ca}^{2+}$-Chelator, 1, 2-bis(2aminophenoxy)ethane-N, N,N',N'-tetraacetic acid (BAPTA) on apoptosis: Cells were preincubated for 90 minutes with increasing amounts of BAPTA, followed by incubation with $40 \mu \mathrm{g} / \mathrm{ml}$ of SC-1 for 24 hours. Apoptotic cells were determined using CellDeath ELISA. An increasing amount of BAPTA had no effect on cell survival after induction of SC-1-induced apoptosis. Treatment with increasing amounts of BAPTA without SC-1 did not show any effect. c, Effect of $\mathrm{Ca}^{2+}$-Chelator BAPTA on CD55 ${ }^{\text {SC-1 }}$ expression: Cell line 23132 was induced with $40 \mu \mathrm{g} / \mathrm{ml}$ of SC-1 in the presence or absence of BAPTA for the periods indicated above, and then membrane lysates and Western blots were prepared and stained with SC-1. Coomassie-stained gels show loading of equal protein concentrations on each lane. A clear increase in $\mathrm{CD}_{5} 5^{\mathrm{SC}-1}$ expression with different kinetic was visible in both experiments. Staining of additional protein is due to an unspecific cross-reaction with the Ku70 autoantigen as described earlier.

$\mathrm{Ca}^{2+}$-chelator, 1, 2-bis(2-aminophenoxy)ethane-N, $\mathrm{N}, \mathrm{N}^{\prime}, \mathrm{N}^{\prime}$-tetraacetic acid (BAPTA), followed by incubation with $40 \mu \mathrm{g} / \mathrm{ml}$ of SC- 1 for 24 hours. The number of apoptotic cells was determined by CellDeath ELISA. Increasing the amount of BAPTA does not have any effect on cell survival, as can be seen in non-SC-1induced cells. Furthermore, there is not a decrease in apoptotic cells after induction of apoptosis with an increasing amount of BAPTA (Fig. 6b). These data indicate that the intracellular $\mathrm{Ca}^{2+}$ concentration is not involved in the regulation of SC-1-induced apoptosis. However, as shown by immunohistochemical studies on cytospins, $\left[\mathrm{Ca}^{2+}\right]_{i}$ might be involved in membrane expression of $\mathrm{CD} 55^{\mathrm{SC}-1}$ and, therefore, may only indirectly be responsible for apoptosis. Neither an increase of membrane expression nor an upsurge of CD55 ${ }^{\mathrm{SC}-1}$ is detected if $\left[\mathrm{Ca}^{2+}\right]_{\mathrm{i}}$ is blocked by BAPTA, as seen after SC-1 binding (data not shown).

To further explore the difference in expression of CD55 ${ }^{\mathrm{SC}-1}$ in untreated and BAPTA-treated cells after SC-1-induction, Western blot analysis was performed with membrane extracts from SC-1-induced cells. An increased expression of CD55 $5^{\mathrm{SC}-1}$ was observed beginning 6 hours after induction of apoptosis and lasting up to 48 hours. However, in uninduced cells CD55 ${ }^{\text {SC-1 }}$ was not detectable because of the low sensitivity of the SC-1 antibody in Western blot analysis. In cells pretreated with BAPTA, an even faster increase in $\mathrm{CD} 55^{\mathrm{SC}-1}$ expression is observed, which also is detectable for up to 48 hours (Fig. 6c). Interestingly, during this apoptotic process, an increase in the expression of the cytoplasmic 70-kd protein, which cross-reacts with SC-1 and was formerly identified as Ku70 autoantigen (Hensel et al, 1999), can also be seen in Western blot analysis.

\section{Discussion}

The SC-1/DAF pathway for tumor-specific apoptosis is new and unique in several aspects. The 82-kd CD55 ${ }^{\mathrm{SC}-1}$ isoform is specifically overexpressed on gastric carcinoma cells, together with the "normal" 
70-kd isoform of CD55 ${ }^{\mathrm{WT}}$. SC-1 apoptosis induces a strong up-regulation of the specific $82-k d$ CD55 $5^{\text {sC-1 }}$ isoform, followed by its internalization. In contrast, the $70-k d$ isoform of CD55 ${ }^{\mathrm{WT}}$, which is also present on stomach cancer cells is not up-regulated or internalized. The apoptotic event is accompanied by cleavage of cytokeratin 18, which indicates the involvement of caspase-6. Caspase- 6 is necessary for SC-1-induced apoptosis, because the inhibition by high concentration VEID-CHO suppresses apoptosis, whereas the inhibition of caspase-3 by DEVD-CHO leads to increased apoptosis. Cleavage of PARP is not observable during SC-1-induced apoptosis, which indicates a pathway different from the one shown for Fas. The apoptotic activity of $\mathrm{CD} 55^{\mathrm{SC}-1}$ is not dependent on $\left[\mathrm{Ca}^{2+}\right]_{\mathrm{i}}$, because the calcium blocker BAPTA does not reduce apoptosis, but BAPTA has some inhibitory effect on the transport of CD55 $5^{\mathrm{SC}-1}$ to the membrane.

Our data show that two isoforms of CD55 are expressed in stomach carcinoma: the ubiquitously distributed $70-\mathrm{kd} \mathrm{CD55}{ }^{\mathrm{WT}}$ and, additionally, the specific 82-kd CD55 ${ }^{\mathrm{SC}-1}$ isoform. Interestingly, both CD55 isoforms show a different regulation after induction of apoptosis. Since there were not any differences found in the transcripts of CD55 in cell line 23132 compared with other published wild-type sequences (Hensel et al, 1999), regulation of the two isoforms must be due to posttranslational events like differential glycosylation, which will have to be examined more closely. The up-regulation of apoptosis-inducing receptors during apoptosis is a feature of these receptors unobserved so far, and the genetic background of this observation has to be further investigated. This up-regulation might be coupled to the function of CD55 in the protection of cells from autologous complement (Cheung et al, 1988). Up-regulation of CD55 by various factors has been observed in noncancerous cells, eg, in endothelial cells (ECs) or human glomerular cells. This up-regulation can be induced by incubating ECs with the membrane attack complex (MAC) and by incubation with anti-CD55 antibodies or various cytokines, such as tumor necrosis factor (TNF)- $\alpha$ or interferon (IFN)- $\gamma$ (Mason et al, 1999). Increased expression of CD55 can also be induced by activation of terminal complement compounds ( $\mathrm{C} 8$ and/or $\mathrm{C} 9$ ) on human glomerular cells (Cosio et al, 1994). It might be suggested that this up-regulation of CD55 results in an elevated resistance to the attack of autologous complement.

So far the inducibility of CD55 expression on tumor cells is not well investigated. An increased expression of the complement regulators CD46, CD55, and CD59 has been shown immunohistochemically on gastrointestinal tumors and might also have a function in the protection of cells from complement attack (Berstad and Brandtzaeg, 1998; Schmitt et al, 1999). Our data show for the first time that CD55 is inducible in stomach cancer cells and leads us to suggest that SC-1 partially mimics complement attack. The higher expression of $\mathrm{CD} 55^{\mathrm{SC}-1}$ is followed by the disappearance of $\mathrm{CD} 55^{\mathrm{SC}-1}$ from the cell membrane, as demonstrated by Western blot analysis and flow cytom- etry. This increase might be a protection mechanism for the cell against the apoptotic mechanism of the SC-1 antibody. This is supported by the finding that the disappearance of $\mathrm{CD}_{5} 5^{\mathrm{SC}-1}$ is observed in nearly all cells, whereas apoptosis, shown by cleavage of cytokeratin 18 , is only visible in approximately $30 \%$ of the cells. Further studies will show whether the disappearance of CD55 from the membrane is related to the protection of cells against apoptosis.

The apoptotic process is accompanied by limited proteolysis of cellular proteins by the caspase family of cysteine proteases (Alnemri et al, 1996), which are mediators of apoptotic cell death (Martin and Green, 1995). One target of these proteases is cytokeratin 18 , a major component of the intermediate filament of simple epithelial cells and tumors derived from such cells (Caulin et al, 1997; Schaafsma et al, 1990). So far, the cleavage of cytokeratin 18 has been observed in chemically induced (etoposide) or UV-light-induced apoptosis. Our data show that cleavage of cytokeratin 18 also occurs in SC-1-induced apoptosis. This cleavage is visible in $30 \%$ of the cells and increases for up to 72 hours after induction of apoptosis, indicating that SC-1-induced apoptosis is slower than chemicalor UV-light-induced apoptosis. Furthermore, this data shows that caspase-6, which performs the initial cleavage of cytokeratin 18 into 26-kd and 22-kd fragments (Caulin et al, 1997), must be a participant in SC-1-induced apoptosis. The necessity of the participation of caspase- 6 was shown by the inhibition of caspase- 6 with VEID-CHO, which reduces the amount of apoptotic cells when using higher concentrations of caspase inhibitor. The increase in apoptotic cell death when using low concentrations $(1-10 \mu \mathrm{M})$ of VEID$\mathrm{CHO}$ and the increase in cell death with increasing amounts of caspase- 3 inhibitor DEVD-CHO indicate a number of differences from apoptosis pathways previously described. This might be due to the bypassing of the inhibited caspases by means of other caspases. These differences from other apoptosis pathways are consistent with the fact that PARP cleavage does not occur in SC-1-induced apoptosis. PARP is a 116-kd protein that detects and binds to DNA strand breaks and is involved in DNA repair (Casciola-Rosen et al, 1996). PARP is cleaved specifically by caspase- 3 after its activation by proteolytic cleavage (Lazebnik et al, 1994). For that reason, cleavage of PARP is widely used as a marker for the induction of apoptosis (Oliver et al, 1998). Whether this observation is due to the low activation of caspase-3 (Hensel et al, 1999) needs to be further investigated. However, caspase-3 does not seem to play any role in SC-1 apoptosis, and this provides further evidence that cleavage of PARP is not obligatory for induction of apoptosis. Recently, it was shown that PARP-/- fibroblasts expressing mutant uncleavable PARP are sensitive to CD95 apoptosis, but with a delayed cell death (Oliver et al, 1998).

Slow kinetics are also visible in SC-1-induced apoptosis, as confirmed by staining with M30 CytoDeath antibody and the slow decrease in expression of topoisomerase $\| l \alpha$. The involvement of the cell-cycle regulator c-myc in apoptotic processes has been 
shown in various experimental systems (Packham and Cleveland, 1995). Activation or overexpression of c-myc induces apoptosis, whereas cells with reduced c-myc expression seem to be resistant to various apoptotic stimuli (Dong et al, 1997). The up-regulation of c-myc expression in SC-1-induced apoptosis leads us to propose that SC-1 apoptosis mediated by $\mathrm{CD} 55^{\mathrm{SC}-1}$ is also dependent on c-myc. It has been shown that c-myc-dependent apoptosis induces cleavage of PARP and activation of caspase-3. Because $\mathrm{Ca}^{2+}$ is also a regulator of some apoptotic processes (Yoshida et al, 1997), we investigated the effect of changes in the intracellular $\mathrm{Ca}^{2+}$ concentration on SC-1-induced apoptosis, and a rapid increase in the $\left[\mathrm{Ca}^{2+}\right]_{i}$ was found. This increase in $\left[\mathrm{Ca}^{2+}\right]_{i}$ is not related to the apoptosis event, because apoptosis cannot be inhibited by the intracellular $\mathrm{Ca}^{2+}$ blocker BAPTA. Yet the differences in the expression pattern shown by Western blot analysis indicate that $\left[\mathrm{Ca}^{2+}\right]_{\mathrm{i}}$ is involved in the regulation of CD55 expression. Also, membrane translocation of CD55 is regulated by $\mathrm{Ca}^{2+}$, because, after the incubation of cells with BAPTA and induction of apoptosis, an increase in membranous staining is not visible (data not shown). Next to an increase of $\mathrm{CD} 55^{\mathrm{SC}-1}$, we found an increase of a second protein of approximately $70 \mathrm{kd}$, which was identified as the Ku70 autoantigen (Hensel et al, 1999) and shows some cross-reaction with the SC-1 antibody. It was shown recently that this protein is involved in the apoptotic process. There was an increase of Ku70 expression found after induction of apoptosis by ionizing radiation in human lung carcinoma cell lines (Brown et al, 2000). Therefore, our data lead us to believe that Ku70 also plays a role in SC-1-induced apoptosis.

Complement-inactivating receptors have been shown to be overexpressed on a variety of tumor cells and represent ideal targets for therapeutic approaches. However, our data have shown that the expression is not stable but, rather, is strongly variable. This limits the use of antibody-mediated cell lysis and vaccination for therapy. For ADCC, high amounts of CD55 inactivate the complement, which is needed by the therapeutical antibodies (Riethmüller et al, 1994), and low expression reduces immunological processes (Durrant et al, 2000).

The induction of apoptosis by the $\operatorname{lgM}$ antibody SC-1 is relatively independent of the number of CD55 receptors. The reason for this is that, shortly after the binding of SC-1 to CD55, the cell increases its amount of CD55 on the surface to protect itself against a presumptive complement attack. This, ironically, does not help the cell to survive but, instead, enhances cell death.

We do not know why stomach cancer cells express two isoforms of CD55 with different glycosylation patterns. It could provide an advantage in protection against autologous complement, and at least it does not have any negative selective effect in vivo. The amounts of circulating antibodies like SC-1 are generally too low to become dangerous for the tumor. However, it would be interesting to examine tissues from other tumors for similar coexpression, and possible targets similar to those on stomach cancer cells could be detected.

Apoptosis is the most effective and safest way to remove tumors from the organism. So far, many apoptosis receptors are known, but none of them are tissue- or cell-specific, or at least overexpressed on tumor cells. The SC-1/CD55 apoptosis mechanism is, so far, unique, but it may be assumed that the search for new tumor-related apoptosis receptors on other malignant cells is likely to succeed, if one begins by looking for mechanisms first, and then for corresponding molecules. This will result in more promising targets for cancer therapy.

\section{Material and Methods}

\section{Cell Culture}

For all assays, the established stomach adenocarcinoma cell line 23132 (Vollmers et al, 1993) was used. Cells were grown to subconfluency in RPMI-1640 (PAA, Vienna, Austria), supplemented with 10\% FCS and penicillin/streptomycin (both 1\%). For the assays described here, cells were detached with trypsin/ EDTA and washed twice with PBS before use. The human hybridoma cell line SC-1 was grown in serumfree RPMI-1640 medium (PFHM-II; Life TechnologiesGibco BRL, Karlsruhe, Germany), using miniPerm Bioreactors (InVitro Systems \& Services, Osterode, Germany).

\section{Purification of the SC-1 Antibody}

The human monoclonal antibody was purified from mass cultures, using cation exchange chromatography followed by gel filtration, as described elsewhere (Vollmers et al, 1998a).

\section{Flow Cytometry}

The cell lines 23132 and HeLa were used for the analysis of CD55 ${ }^{\mathrm{SC}-1}$ and $\mathrm{CD} 55^{\mathrm{WT}}$ receptor expression. Cells were grown to subconfluency in complete medium, and then purified SC-1 was added to a final concentration of $40 \mu \mathrm{g} / \mathrm{ml}$ for the indicated periods. As a control, cells were incubated in RMPI- 1640 medium with $10 \%$ FCS without SC-1 antibody. Cells were harvested after 24,48 , and 72 hours by detaching with Trypsin/EDTA. The cells were subsequently incubated on ice with SC-1, anti-CD55 antibody (clone 143-30, DPC Biermann, Bad Nauheim, Germany), and human (Chrompure human IgM; Dianova, Hamburg, Germany) or mouse isotype-matched (mouse IgG1; Pharmingen, Heidelberg, Germany) control antibodies for 15 minutes. This was followed by incubation with a FITC-labeled rabbit anti-human IgM antibody (Dianova) or an R-phycoerythrin-labeled donkey antimouse IgG (Dianova), respectively, for 15 minutes on ice. Antibodies were optimally diluted in PBS containing $0.01 \%$ sodiumazide. Cells were analyzed by flow cytometry (FACScan; Becton Dickinson, San Jose, California). 


\section{Immunohistochemical Staining of Cytospin Preparations}

Subconfluently grown cells were incubated with purified SC-1 antibody diluted to $40 \mu \mathrm{g} / \mathrm{ml}$ in complete growth medium and incubated for up to 48 hours. Adherent and detached cells were collected after the prescribed times, centrifuged, and resuspended in complete growth medium. After counting cells, cytospins were prepared and air-dried at room temperature overnight. Cytospins were blocked with BSA (15 $\mathrm{mg} / \mathrm{ml}$ ) diluted in PBS for 30 minutes. The cytospins were incubated for 1 hour with M30 CytoDeath antibody (Roche Biochemicals, Mannheim, Germany) and washed for 30 minutes in PBS, followed by incubation with peroxidase-labeled rabbit anti-mouse conjugate (Dako, Glostrup, Denmark) diluted 1:25 in PBS/BSA. After washing for 30 minutes with PBS, staining was performed with diaminobenzidine (0.05\%)-hydrogen peroxide $(0.02 \%)$ for 10 minutes at room temperature. The reaction was stopped under running tap water, and sections were counterstained with hematoxylin.

\section{Inhibition of Caspases and Apoptosis Assay}

Cells were preincubated for 24 hours with the indicated concentrations of caspase inhibitors. Then the purified SC-1 antibody was added to the final concentration of $40 \mu \mathrm{g} / \mathrm{ml}$, and plates were incubated for a further 24 hours. Apoptosis was detected using the CellDeath Detection ${ }^{\text {plus }}$ kit (Roche Biochemicals) following the manufacturer's protocols.

\section{Preparation of Cell Lysates after Induction with SC-1}

Cell line 23132 was grown to subconfluency on $100-\mathrm{mm}$ cell-culture plates. Then the SC-1 antibody was added to a final concentration of $30 \mu \mathrm{g} / \mathrm{ml}$ and incubated for the periods indicated. After incubation, culture plates were washed once with PBS, and subsequently cells were directly lysed with SDS buffer (50 mM Tris/Cl, pH 6.8; $10 \mathrm{~mm}$ DTT; 2\% [w/v] SDS; $10 \%[\mathrm{v} / \mathrm{v}]$ glycerol). Cell lysates were collected with a rubber policeman.

For preparation of membrane proteins, harvested cells were resuspended in hypotonic buffer $(20 \mathrm{~mm}$ HEPES, $3 \mathrm{~mm} \mathrm{KCl,} 3 \mathrm{~mm} \mathrm{MgCl}$ ), incubated on ice (15 minutes), and sonicated (5 minutes), and the nuclei were pelleted by centrifugation $(10,000 \times g, 10 \mathrm{~min}-$ utes). The membranes were pelleted by centrifugation $(100,000 \times g, 30$ minutes) and resuspended in membrane lysis buffer (50 mM HEPES, pH 7.4; $0.1 \mathrm{~mm}$ EDTA; $1 \mathrm{M} \mathrm{NaCl} ; 10 \%$ glycerol; and $1 \%$ Triton X-100). Complete protease inhibitor (Roche Biochemicals) was added to all solutions.

\section{Gel Electrophoresis and Blotting}

SDS-PAGE under reducing conditions and Western blotting of proteins were performed using standard protocols as described elsewhere (Vollmers et al, 1997). In brief, blotted nitrocellulose membranes were blocked with PBS containing $0.05 \%(\mathrm{v} / \mathrm{v})$ Tween-20 (except for SC-1) and 5\% (w/v) low-fat milk powder, followed by a 1-hour incubation with primary antibody. The antibodies were used in the indicated dilutions: SC-1, $10 \mu \mathrm{g} / \mathrm{ml}$; mouse anti-topoisomerase $\| l \alpha$, 1:1000 (Neomarkers, Baesweiler, Germany); anti-cmyc, 1:1000; anti-CD55, 1:1000 (Santa Cruz, Heidelberg, Germany); and anti-PARP, 1:1000 (Pharmingen). The secondary antibodies (peroxidase-coupled rabbit anti-mouse IgG or rabbit anti-goat antibody [Dianova]) were detected with the SuperSignal chemiluminescence kit from Pierce (KMF, St. Augustin, Germany).

\section{Measurement of Intracellular Free Calcium $\left[\mathrm{Ca}^{2+}\right]_{i}$}

$\left[\mathrm{Ca}^{2+}\right]_{\mathrm{i}}$ was determined using the $\mathrm{Ca}^{2+}$-sensitive dye, Fura 2-AM, as described (Grynkiewicz et al, 1985). In brief, cells were incubated with Ringer solution (122.5 $\mathrm{mm} \mathrm{NaCl} ; 5.4 \mathrm{~mm} \mathrm{KCl} ; 1.2 \mathrm{mM} \mathrm{CaCl}_{2} ; 0.8 \mathrm{~mm} \mathrm{MgCl}_{2} ; 1$ $\mathrm{mm} \mathrm{NaH} 2 \mathrm{PO}_{4} ; 5.5$ mm glucose; 10 mm HEPES, pH 7.4) containing Fura 2-AM in a final concentration of $5 \mu \mathrm{M}$ for 15 minutes. After rinsing, the coverslips were mounted on the stage of an inverted Axiovert 100 TV microscope (Zeiss, Jena, Germany; magnification, $\times 400$ ). The fluorescence signal was monitored at 500 $\mathrm{nm}$ with excitation wavelengths alternating between 334 and $380 \mathrm{~nm}$, using a 100 Watt xenon lamp and an automatic filter change device (Zeiss). Filter change and data acquisition were controlled by Attofluor software (Zeiss). $\left[\mathrm{Ca}^{2+}\right]_{i}$ was calculated according to the method of Grynkiewicz et al (1985), with a dissociation constant of $225 \mathrm{~nm}$. The maximum and minimum fluorescence ratios $\left(R_{\max }\right.$ and $\left.R_{\min }\right)$ were measured after addition of the calibration solutions. $R_{\max }$ was measured in the presence of Ringer solution containing $3 \mathrm{mM} \mathrm{Ca}^{2+}$ and $1 \mu \mathrm{M}$ ionomycin, and $\mathrm{R}_{\min }$ was measured in the presence of $\mathrm{Ca}^{2+}$-free Ringer solution containing $3 \mathrm{~mm}$ ethylenebis(oxyethylenenitrilo)tetraacetic acid (EGTA) and $1 \mu \mathrm{m}$ ionomycin.

\section{Inhibition of Intracellular Calcium Release}

Cells were washed once with PBS and incubated for 3 hours with the indicated concentrations of BAPTA diluted in complete growth medium. Then purified SC-1 antibody was added to a final concentration of $40 \mu \mathrm{g} / \mathrm{ml}$. As a control, the same cells were incubated without SC-1. Cells were incubated in a humidified incubator for an additional period of time as indicated and then used for either preparation of membrane extracts or performing CellDeath ELISA as described below, or they were fixed with $3 \%$ paraformaldehyde for morphological analysis. Cellculture plates were analyzed for morphologic changes with the aid of a light microscope.

\section{Acknowledgements}

The authors thank Ms. E. Wozniak and Ms. T. Pohle for excellent technical assistance, Mr. E. Schmitt for preparing the artwork, and Ms. A. Stack for improving the manuscript. 


\section{References}

Alnemri ES, Livingston DJ, Nicholson DW, Salvesen G, Thornberry NA, Wong WW, and Yuan J (1996). Human ICE/CED-3 protease nomenclature. Cell 87:171.

Asch AS, Kinoshita T, Jaffe EA, and Nussenzweig V (1986). Decay-accelerating factor is present on cultured human umbilical vein endothelial cells. J Exp Med 163:221-226.

Berstad AE and Brandtzaeg P (1998). Expression of cell membrane complement regulatory glycoproteins along the normal and diseased human gastrointestinal tract. Gut 42: 522-529.

Blok VT, Daha MR, Tijsma O, Harris CL, Morgan BP, Fleuren GJ, and Gorter A (1998). A bispecific monoclonal antibody directed against both the membrane-bound complement regulator CD55 and the renal tumor-associated antigen G250 enhances $\mathrm{C} 3$ deposition and tumor cell lysis by complement. J Immunol 160:3437-3443.

Brodsky RA, Vala MS, Barber JP, Medof ME, and Jones RJ (1997). Resistance to apoptosis caused by PIG-A gene mutations in paroxysmal nocturnal hemoglobinuria. Proc Natl Acad Sci USA 94:8756-8760.

Brown KD, Lataxes TA, Shangary S, Mannino JL, Giardina JF, Chen J, and Baskaran R (2000). lonizing radiation exposure results in up-regulation of Ku70 via a p53/ataxiatelangiectasia-mutated protein-dependent mechanism. J Biol Chem 275:6651-6656.

Caras IW, Davitz MA, Rhee L, Weddell G, Martin DWJ, and Nussenzweig V (1987). Cloning of decay-accelerating factor suggests novel use of splicing to generate two proteins. nature 325:545-549.

Casciola-Rosen L, Nicholson DW, Chong T, Rowan KR, Thornberry NA, Miller DK, and Rosen A (1996). Apopain/ CPP32 cleaves proteins that are essential for cellular repair: A fundamental principle of apoptotic death. J Exp Med 183:1957-1964.

Caulin C, Salvesen GS, and Oshima RG (1997). Caspase cleavage of keratin 18 and reorganization of intermediate filaments during epithelial cell apoptosis. J Cell Biol 138: 1379-1394.

Cheung NK, Walter El, Smith-Mensah WH, Ratnoff WD, Tykocinski ML, and Medof ME (1988). Decay-accelerating factor protects human tumor cells from complement- mediated cytotoxicity in vitro. J Clin Invest 81:1122-1128.

Cosio FG, Shibata T, Rovin BH, and Birmingham DJ (1994). Effects of complement activation products on the synthesis of decay accelerating factor and membrane cofactor protein by human mesangial cells. Kidney Int 46:986-992.

Devitt A, Moffat OD, Raykundalia C, Capra JD, Simmons DL, and Gregory CD (1998). Human CD14 mediates recognition and phagocytosis of apoptotic cells. Nature 392:505-509.

Dong J, Naito M, and Tsuruo T (1997). c-Myc plays a role in cellular susceptibility to death receptor- mediated and chemotherapy-induced apoptosis in human monocytic leukemia U937 cells. Oncogene 15:639-647.

Durrant LG, Buckley DJ, Robins RA, and Spendlove I (2000). 105Ad7 cancer vaccine stimulates anti-tumor helper and cytotoxic T- cell responses in colorectal cancer patients but repeated immunisations are required to maintain these responses. Int J Cancer 85:87-92.
Durrant LG, Doran M, Austin EB, and Robins RA (1995). Induction of cellular immune responses by a murine monoclonal anti- idiotypic antibody recognizing the 791Tgp72 antigen expressed on colorectal, gastric and ovarian human tumors. Int J Cancer 61:62-66.

Gorter A and Meri S (1999). Immune evasion of tumor cells using membrane-bound complement regulatory proteins. Immunol Today 20:576-582.

Grynkiewicz G, Poenie M, and Tsien RY (1985). A new generation of $\mathrm{Ca} 2+$ indicators with greatly improved fluorescence properties. J Biol Chem 260:3440-3450.

Hara T, Matsumoto M, Fukumori Y, Miyagawa S, Hatanaka M, Kinoshita T, Seya T, and Akedo H (1993). A monoclonal antibody against human decay-accelerating factor (DAF, CD55), D17, which lacks reactivity with semen-DAF. Immunol Lett 37:145-152.

Hensel F, Hermann R, Schubert C, Abé N, Schmidt K, Franke A, Shevchenko A, Mann M, Müller-Hermelink HK, and Vollmers HP (1999). Characterization of glycosylphosphatidylinositol-linked molecule CD55/decay-accelerating factor as the receptor for antibody SC-1-induced apoptosis. Cancer Res 59:5299-5306.

Hofman P, Hsi BL, Manie S, Fenichel P, Thyss A, and Rossi $B$ (1994). High expression of the antigen recognized by the monoclonal antibody GB24 on human breast carcinomas: a preventive mechanism of malignant tumor cells against complement attack? Breast Cancer Res Treat 32:213-219.

Koretz K, Bruderlein S, Henne C, and Moller P (1992). Decay-accelerating factor (DAF, CD55) in normal colorectal mucosa, adenomas and carcinomas. Br J Cancer 66:810814.

Lazebnik YA, Kaufmann SH, Desnoyers S, Poirier GG, and Earnshaw WC (1994). Cleavage of poly(ADP-ribose) polymerase by a proteinase with properties like ICE. nature 371:346347.

Lublin DM, Krsek-Staples J, Pangburn MK, and Atkinson JP (1986). Biosynthesis and glycosylation of the human complement regulatory protein decay-accelerating factor. $\mathrm{J}$ Immunol 137:1629-1635.

Martin SJ and Green DR (1995). Protease activation during apoptosis: Death by a thousand cuts? Cell 82:349-352.

Mason JC, Yarwood H, Sugars K, Morgan BP, Davies KA, and Haskard DO (1999). Induction of decay-accelerating factor by cytokines or the membrane-attack complex protects vascular endothelial cells against complement deposition. Blood 94:1673-1682.

Nicholson-Weller A, March JP, Rosen CE, Spicer DB, and Austen KF (1985). Surface membrane expression by human blood leukocytes and platelets of decay-accelerating factor, a regulatory protein of the complement system. Blood 65: 1237-1244.

Niehans GA, Cherwitz DL, Staley NA, Knapp DJ, and Dalmasso AP (1996). Human carcinomas variably express the complement inhibitory proteins CD46 (membrane cofactor protein), CD55 (decay-accelerating factor), and CD59 (protectin). Am J Pathol 149:129-142.

Oliver FJ, de la Rubia G, Rolli V, Ruiz-Ruiz MC, de Murcia G, and Murcia JM (1998). Importance of poly(ADP-ribose) polymerase and its cleavage in apoptosis. Lesson from an uncleavable mutant. J Biol Chem 273:33533-33539. 
Packham G and Cleveland JL (1995). c-Myc and apoptosis. Biochim Biophys Acta 1242:11-28.

Parolini I, Sargiacomo M, Lisanti MP, and Peschle C (1996). Signal transduction and glycophosphatidylinositol-linked proteins (lyn, Ick, CD4, CD45, G proteins, and CD55) selectively localize in Triton-insoluble plasma membrane domains of human leukemic cell lines and normal granulocytes. Blood 87:3783-3794.

Riethmüller G, Schneider Gadicke E, Schlimok G, Schmiegel W, Raab R, Hoffken K, Gruber R, Pichlmaier H, Hirche H, and Pichlmayr R (1994). Randomized trial of monoclonal antibody for adjuvant therapy of resected Dukes' C colorectal carcinoma. German Cancer Aid 17-1A Study Group. Lancet 343:1177-1183.

Schaafsma HE, Ramaekers FC, van Muijen GN, Lane EB, Leigh IM, Robben H, Huijsmans A, Ooms EC, and Ruiter DJ (1990). Distribution of cytokeratin polypeptides in human transitional cell carcinomas, with special emphasis on changing expression patterns during tumor progression. Am $\mathrm{J}$ Pathol 136:329-343.

Schmitt CA, Schwaeble W, Wittig BM, Meyer zBK, and Dippold WG (1999). Expression and regulation by interferongamma of the membrane-bound complement regulators CD46 (MCP), CD55 (DAF) and CD59 in gastrointestinal tumors. Eur J Cancer 35:117-124.

Shapiro DN, Jones BG, Shapiro LH, Dias P, and Houghton PJ (1994). Antisense-mediated reduction in insulin-like growth factor-I receptor expression suppresses the malignant phenotype of a human alveolar rhabdomyosarcoma. J Clin Invest 94:1235-1242.

Shenoy-Scaria AM, Kwong J, Fujita T, Olszowy MW, Shaw AS, and Lublin DM (1992). Signal transduction through decay-accelerating factor. Interaction of glycosylphosphatidylinositol anchor and protein tyrosine kinases p56lck and p59fyn 1. J Immunol 149:3535-3541.
Shibuya K, Abe T, and Fujita T (1992). Decay-accelerating factor functions as a signal transducing molecule for human monocytes. J Immunol 149:1758-1762.

Spendlove I, Li L, Carmichael J, and Durrant LG (1999). Decay accelerating factor (CD55): A target for cancer vaccines? Cancer Res 59:2282-2286.

Vollmers HP, Dämmrich J, Hensel F, Ribbert H, MeyerBahlburg A, Ufken-Gaul T, v Korff M, and Müller-Hermelink HK (1997). Differential expression of apoptosis receptors on diffuse and intestinal type stomach carcinoma. Cancer 79: 433-440.

Vollmers HP, Hensel F, Hermann R, Dämmrich J, Wozniak E, Gessner P, Herrmann B, Zimmermann U, and MüllerHermelink HK (1998a). Tumor-specific apoptosis by the human monoclonal antibody SC-1: A new therapeutical approach for stomach cancer. Oncology Reports 5:35-40.

Vollmers HP, O'Connor R, Müller J, Kirchner T, and MüllerHermelink HK (1989). SC-1, a functional human monoclonal antibody against autologous stomach carcinoma cells. Cancer Res 49:2471-2476.

Vollmers HP, Stulle K, Dämmrich J, Pfaff M, Papadopoulos T, Betz C, Saal K, and Müller-Hermelink HK (1993). Characterization of four new gastric cancer cell lines. Virchows Arch $B$ Cell Pathol Incl Mol Pathol 63:335-343.

Vollmers HP, Zimmermann U, Krenn V, Timmermann W, Illert B, Hensel F, Hermann R, Thiede A, Wilhelm M, Rückle-Lanz H, Reindl L, and Müller-Hermelink HK (1998b). Adjuvant therapy for gastric adenocarcinoma with the apoptosisinducing human monoclonal antibody SC-1: first clinical and histopathological results. Oncol Rep 5:549-552.

Yoshida R, Sanchez-Bueno A, Yamamoto N, and EinagaNaito K (1997). $\mathrm{Ca}^{2+}$-dependent, Fas- and perforinindependent apoptotic death of allografted tumor cells by a type of activated macrophage. J Immunol 159:15-21. 